\title{
Predictors of patient reluctance to wake early in the morning for bowel preparation for colonoscopy: a precolonoscopy survey in city-wide practice
}

\section{(ㄷ)(i) $\Theta$}

Authors

L. A. Shafer1,2,3, J. R. Walker ${ }^{3,4}$, C. Waldman ${ }^{1,5}$, V. Michaud ${ }^{1}$, C. Yang1 ${ }^{1}$ C. N. Bernstein ${ }^{1,3}$, L. Hathout ${ }^{1}$, J. Park ${ }^{6,7}$, J. Sisler ${ }^{7,8}$, K. Wittmeier ${ }^{9}$, G. Restall ${ }^{10}$, H. Singh ${ }^{1,2,3,7}$

Institutions

1 Department of Internal Medicine, University of Manitoba, Winnipeg, Manitoba, Canada

2 Department of Community Health Sciences, University of Manitoba, Winnipeg, Manitoba, Canada

3 IBD Clinical and Research Centre, University of Manitoba, Winnipeg, Manitoba, Canada

4 Department of Clinical Health Psychology, University of Manitoba, Winnipeg, Manitoba, Canada

5 Faculty of Nursing, University of Manitoba, Winnipeg, Manitoba, Canada

6 Department of Surgery, University of Manitoba, Winnipeg, Manitoba, Canada

7 CancerCare Manitoba, Department of Epidemiology and Cancer Registry, Winnipeg, Manitoba, Canada

8 Department of Family Medicine, University of Manitoba, Winnipeg, Manitoba, Canada

9 Department of Pediatrics and Child Health, University of Manitoba, Winnipeg, Manitoba, Canada

10 Department of Occupational Therapy, College of Rehabilitation Sciences, Rady Faculty of Health Sciences, University of Manitoba, Winnipeg, Manitoba, Canada

submitted 6.10.2017

accepted after revision 22.1.2018

\section{Bibliography}

DOI https://doi.org/10.1055/s-0044-102298 |

Endoscopy International Open 2018; 06: E706-E713

(c) Georg Thieme Verlag KG Stuttgart · New York

ISSN 2364-3722

Corresponding author

Harminder Singh, MD MPH, Section of Gastroenterology, University of Manitoba, 805-715 McDermot Avenue,

Winnipeg, Manitoba, Canada R3E3P4

Fax: +1-204-789-3972

Harminder.Singh@umanitoba.ca

\section{ABSTRACT}

Introduction Many endoscopists do not use split-dose bowel preparation (SDBP) for morning colonoscopies. Despite SDBP being recommended practice, they believe patients will not agree to take early morning bowel preparation (BP). We assessed patients' opinions about waking early for BP.

Methods A self-administered survey was distributed between 08/2015 and 06/2016 to patients in Winnipeg, Canada when they attended an outpatient colonoscopy. Logistic regression was performed to determine predictors of reluctance to use early morning BP.

Results Of the 1336 respondents (52\% female, median age 57 years), $33 \%$ had used SDBP for their current colonoscopy. Of the 1336 , $49 \%$ were willing, $24 \%$ neutral, and $27 \%$ reluctant to do early morning BP. Predictors of reluctant versus willing were number of prior colonoscopies (OR 1.20; $95 \% \mathrm{Cl}$ : $1.07-1.35$ ), female gender (OR 1.65; $95 \% \mathrm{Cl}$ : 1.19-2.29), unclear BP information (OR 1.86; $95 \% \mathrm{Cl}$ : $1.21-2.85)$, high BP anxiety (OR 2.02; $95 \% \mathrm{Cl}: 1.35-3.02$ ), purpose of current colonoscopy being bowel symptoms (OR 1.40; $95 \% \mathrm{Cl}: 1.00-1.97)$, use of $4 \mathrm{~L}$ of polyethylene glycol laxative (OR 1.45; $95 \% \mathrm{Cl}: 1.02-2.06$ ), not having SDBP (OR 1.96; $95 \% \mathrm{Cl}: 1.31-2.93$ ), and not having finished the laxative for the current colonoscopy (OR 1.66; $95 \% \mathrm{Cl}$ : $1.01-2.73)$. Most of the same predictors were identified when reluctance was compared to willing or neutral, and in ordinal logistic regression.

Conclusions Almost three-quarters of patients do not express reluctance to get up early for BP. Among those who are reluctant, improving $\mathrm{BP}$ information, allaying BP-related anxiety, and use of low volume BP may increase acceptance of SDBP.

丹 Supplemental material Online content viewable at: https://doi.org/10.1055/s-0044-102298 


\section{Introduction}

A good bowel preparation (BP) plays an important role in ensuring an accurate, complete, and safe colonoscopy examination. Despite its importance, bowel cleansing for colonoscopies has been reported to be poor in up to $20-40 \%$ of cases [1], which can compromise patient care and outcomes. Poor bowel cleansing leads to increased risks of complications, longer procedure times, and increased rates of missed lesions, including colorectal polyps and cancers [2 -4]. Inadequate bowel cleansing is also a common reason for early repeat procedures.

BP conducted the day before a colonoscopy clears fecal material from the colon [5]. However, after the fecal material has been cleared, more material - including new fecal material, mucus, secretions - begins to re-enter the colon [6,7]. Thus, preparation starts to deteriorate as time passes from the administration of the bowel preparation. This is the primary reason why a split-dose bowel preparation (SDBP), in which the second dose is taken close to the timing of the colonoscopy, was suggested over 20 years ago [8]. Another reason to split the dose, frequently unrecognized, is to increase patient tolerance $[1,9,10]$. Patient tolerance of SDBP may be higher due to individuals needing to consume a lower amount of the laxative at a time, contributing to fewer nocturnal awakenings or less intense bowel movements [11].

Evidence supporting improved bowel cleansing with SDBP compared with a day-before preparation has been overwhelming [12 - 17]. A meta-analysis of 29 randomized controlled trials suggested an absolute rate difference of $22 \%$ more adequate cleansing with SDBP (85\%) than with non-SDBP (63\%) [15]. It is recommended that the colonoscopy should be performed within 4 hours of the last dose of the SDBP $[15,17]$. European and North American guidelines now strongly recommend the use of SDBP for all colonoscopies [1, 3-5, 18, 19].

Despite the guidelines and the evidence of benefits of SDBP, many endoscopists are reluctant to ask their morning colonoscopy patients to take SDBP because they believe that patients will not agree to waking early to take the second part of the laxative [20-22]. There are limited data from routine clinical practices on patients' willingness to wake early in the morning for BP and predictors of reluctance. A study from a tertiary care center limited to patients undergoing colonoscopy for average risk CRC screening reported that $15 \%$ were not compliant with SDBP [23]. A study from Italy gave patients an information sheet on the benefits of SDBP [20]. Patients were then provided the option of day before or SDBP and $38 \%$ chose day before preparation. Predictors of choosing day before preparation included colonoscopy appointment before $1000 \mathrm{~h}$, travel time $>1$ hour, low education level, and female gender. In that study, all patients used $4 \mathrm{~L}$ of polyethylene glycol (PEG) BP, and all were undergoing their first colonoscopy. Many patients undergo repeat colonoscopies and use of low volume BP is common. Hence, it is important to assess the opinions of those with varying numbers of previous colonoscopies and colonoscopy preparation experiences to identify factors that may be modified in instructing patients about bowel preparation.
In this study, we assessed in usual clinical practice, colonoscopy patients' opinions about waking up for BP early in the morning, and evaluated factors associated with reluctance to conduct early morning BP.

\section{Methods}

\section{Study population}

A self-administered anonymous survey (see Supplementary Fig. 2) was distributed between August 2015 and June 2016 to adult patients immediately before their outpatient colonoscopy in six hospitals and two ambulatory care centers in Winnipeg, Manitoba, Canada. Approximately $85 \%$ of the colonoscopies in Winnipeg are performed in the six hospitals in the city and their affiliated endoscopy units, and the rest in two ambulatory care centers.

Participants were invited into the study if there was enough time before their procedure to complete the survey. Inclusion criteria included patients' willingness to complete the self-administered survey while sitting in the waiting room, and the ability to read and respond in English. The colonoscopy centers were frequently busy and the survey was only distributed when staff had adequate time to explain the survey to patients waiting for their procedure.

\section{The survey}

The survey included items on demographic characteristics, reason for the current colonoscopy, previous experience with colonoscopy, whether or not the patient was going directly to endoscopy (i.e. meeting the endoscopist for the first time on the day of the procedure), BP procedure used, anxiety about the colonoscopy, knowledge/information needs around colonoscopy and how willing the patient would be to wake early in the morning to complete the BP for their next colonoscopy. The question about willingness to wake early used the example of waking at $0400 \mathrm{~h}$ to take BP for a colonoscopy at $0800 \mathrm{~h}$. The survey took about 10 to 20 minutes to complete. The questionnaire was first pilot tested among eight patients experienced with colonoscopies and eight endoscopists.

Three self-reported anxiety scores were obtained from each respondent using visual analogue scales [24,25]: anxiety about the BP, anxiety about the colonoscopy procedure, and anxiety about the colonoscopy results. Each score was obtained by asking the respondent to assess their level of anxiety by placing a mark such as the one below:

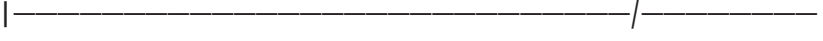 \\ Not at all anxious \\ Extremely anxious}

The mark was then translated into a score from 0 to 100 by measuring placement of the line on the scale.

\section{Statistical analysis}

Background characteristics of the respondents are described. Patients indicated whether they were very willing, willing, neutral, reluctant, or very reluctant to wake up early in the morning for BP. In the analysis, willing and very willing responses were 
combined, as were reluctant and very reluctant responses. The proportion of patients willing, neutral, or reluctant to wake early in the morning for BP was described for each potential predictor in the subsequent analyses. Multivariable logistic regression analyses were performed to determine predictors of reluctance to use early morning BP. In separate logistic regression analysis models, those who were reluctant to use early morning BP were compared to people who were willing, people who were neutral, and people who were willing or neutral toward use of early morning BP.

In some analyses, the continuous anxiety scales were dichotomized. A score of 70 or more was chosen to indicate a high level of anxiety, because this score represented approximately the top quartile of the anxiety score among all patients.

Our main response variable was ordered from reluctant to neutral to willing to wake up early morning for BP. As such, in addition to ordinary logistic regression, we assessed whether our conclusions would be the same using ordinal logistic regression. These results are provided as supplementary material.

The odds from our logistic regressions were transformed into probabilities using the formula:

Probability $=$ Odds $/(1+$ Odds $)[26]$

To visually inspect the importance of different variables in predicting the likelihood of being reluctant to undergo early morning BP, we graphed the probabilities of being reluctant, neutral, or willing to undergo BP early in the morning, given different levels of the independent variables in the ordinal logistic regression model. In total, 16 permutations of levels of the independent variables were graphed, and probabilities of being reluctant, neutral, or willing to undergo early morning BP were compared.

\section{Ethical approval}

This study was approved by the University of Manitoba Health Research Ethics Board.

\section{Results}

At two of the hospitals, the survey was distributed and collected by clinical staff and the response rate could be assessed; it was $86 \%$ at both locations. The other locations were not able to collect response rate information as staff were too busy to document the number of persons who refused to complete the surveys, but all locations indicated that the survey was well accepted. Of the 1336 respondents, 52.2\% were women and the median age was 57 years (IQR 49-65). Participant ages ranged from 16 to 91 years. Just over one-quarter $(26.5 \%)$ were reluctant or very reluctant to complete BP in the early morning, $24.0 \%$ were neutral, and $49.5 \%$ were willing or very willing ( $>$ Table 1 ).

Although type of BP used for the current colonoscopy was based on advice from their endoscopist, those who used SDBP (morning or afternoon) were less likely to be reluctant to do early morning BP for a subsequent colonoscopy than those who used day before BP (21.2\% versus $29.5 \%$ reluctant respectively, $P<0.001)$. Furthermore, among those who used SDBP for their current colonoscopy, $33.3 \%$ thought that waking early in the morning for BP would be difficult or very difficult, while $46.5 \%$ of those who had conducted day before BP thought that an early morning BP would be difficult or very difficult ( $P$ value for difference $<0.001$ )

\section{Predictors of reluctance to wake early for bowel preparation}

In a model that excluded those who were neutral toward early morning waking for BP ( $\triangleright$ Table 2, Model 1), the respondent characteristics associated with reluctance to wake early were female gender (OR 1.65), number of previous colonoscopies (OR 1.20 per colonoscopy), receiving unclear BP information (OR 1.86), having a BP anxiety score $>70$ (OR 2.02), indication for current colonoscopy being symptoms (OR 1.40), using $4 \mathrm{~L}$ of PEG laxative (OR 1.45), not having used SDBP for the current colonoscopy (OR 1.96), and not having finished the laxative for the current colonoscopy (OR 1.66). Reluctance increased with increasing number of prior colonoscopies; for example, a respondent who had had three previous colonoscopies was estimated to be 1.73 times more likely $(95 \% \mathrm{Cl} 1.23-2.46)$ to be reluctant than willing ( $>$ Table 2 , Model 1 ) to perform an early morning BP than one whose current colonoscopy was their first one. This estimate is derived by raising the OR for previous colonoscopies to the power of $3\left(1.20^{3}=1.73\right)$. In a model comparing reluctant to neutral, the associations were similar to those found in the model described above, but less strong; that is, although the odds ratios were similar, fewer potential predictors were statistically significant ( $\triangleright$ Table 2, Model 2).

In ordinal logistic regression modeling (Supplementary Table1, right column), both the statistically significant predictors, as well as the odds ratios, were similar to those found in the ordinary logistic regression modeling. Under numerous permutations of the different levels of the statistically significant predictors from the ordinal logistic regression model, we have displayed, in Supplementary Fig.1a,b, the probability of being reluctant, neutral, or willing to undergo early morning BP, depending on the level of each of the following significant predictors from the ordinal logistic regressions: gender, clarity of BP information, having conducted a SDBP, having finished their laxative, and their BP anxiety score. As an example, under almost all permutations of the different levels of independent variables (e.g., female versus male, having received clear versus unclear bowel preparation information, having split the dose for the current colonoscopy versus having conducted a single-dose preparation, etc.), the probability of being willing to wake early for BP was higher than the probability of being reluctant, at low levels of anxiety about the bowel preparation. A notable exception was among women who received unclear BP information, had not conducted an SDBP for their current colonoscopy, and had not finished the laxative for their current colonoscopy (Supplementary Fig.1a, panel 8). Among this group, even those with very low levels of anxiety had a relatively high probability of reluctance. The probability of reluctance among this group was almost the same as the probability of willingness when anxiety about the BP was near 0 , and it increased to almost $75 \%$ when anxiety about the BP was near its highest possible score of 100 . Other variables in Supplemen- 
- Table 1 Characteristics of the study respondents by proportion reluctant, neutral, and willing to do an early morning bowel preparation (\%).

\begin{tabular}{|c|c|c|c|}
\hline & $\begin{array}{l}\text { Reluctant } \\
(n=354)\end{array}$ & $\begin{array}{l}\text { Neutral } \\
(n=321)\end{array}$ & $\begin{array}{l}\text { Willing } \\
(n=661)\end{array}$ \\
\hline \multicolumn{4}{|l|}{ Survey location $(n=1336)$} \\
\hline - Teaching hospital (28\%) & 25 & 25 & 50 \\
\hline - Other hospital (63\%) & 26 & 24 & 50 \\
\hline - Clinic (9\%) & 32 & 21 & 47 \\
\hline \multicolumn{4}{|l|}{ Gender $(n=1301)^{1}$} \\
\hline - Male (48\%) & 21 & 24 & 54 \\
\hline - Female (52\%) & 31 & 24 & 44 \\
\hline \multicolumn{4}{|l|}{ Age $(n=1293)$} \\
\hline - Mean age & 56.7 & 55.8 & 56.0 \\
\hline - Median age & 58 & 57 & 57 \\
\hline \multicolumn{4}{|l|}{ Education $(n=1212)$} \\
\hline - <Grade 12 (16\%) & 25 & 27 & 47 \\
\hline - Grade $12(20 \%)$ & 26 & 29 & 45 \\
\hline - <4 years post-HS (40\%) & 28 & 23 & 49 \\
\hline - $4+$ years post-HS ( $24 \%)$ & 24 & 20 & 56 \\
\hline \multicolumn{4}{|l|}{ Marital status $(n=1293)$} \\
\hline - Married (76\%) & 25 & 24 & 51 \\
\hline - Separated/divorced (10\%) & 31 & 25 & 44 \\
\hline - Widowed (5\%) & 33 & 19 & 48 \\
\hline - Single (9\%) & 31 & 26 & 43 \\
\hline \multicolumn{4}{|c|}{ How much bowel prep info received $(n=1258)$} \\
\hline - None (4\%) & 36 & 16 & 48 \\
\hline - Right amount (65\%) & 25 & 24 & 51 \\
\hline - Too little (30\%) & 28 & 26 & 46 \\
\hline - Too much (1\%) & 33 & 7 & 60 \\
\hline \multicolumn{4}{|c|}{ Clarity of bowel prep info $(n=1300)^{1}$} \\
\hline - Confusing (6\%) & 46 & 16 & 38 \\
\hline " Somewhat clear (12\%) & 33 & 24 & 43 \\
\hline - Clear (82\%) & 24 & 25 & 51 \\
\hline \multicolumn{4}{|c|}{ Split prep for current colonoscopy $(n=1304)^{1}$} \\
\hline - Yes (33\%) & 21 & 22 & 57 \\
\hline - No (67\%) & 30 & 25 & 45 \\
\hline
\end{tabular}

Table 1 (Continuation)

\begin{tabular}{|c|c|c|c|}
\hline & $\begin{array}{l}\text { Reluctant } \\
(n=354)\end{array}$ & $\begin{array}{l}\text { Neutral } \\
(n=321)\end{array}$ & $\begin{array}{l}\text { Willing } \\
(n=661)\end{array}$ \\
\hline \multicolumn{4}{|c|}{ Anxiety scores (on scale of 0 to 100 ) } \\
\hline \multicolumn{4}{|c|}{ Bowel prep anxiety $(n=1303)^{1}$} \\
\hline - Score $<70(82 \%)$ & 23 & 25 & 52 \\
\hline - Score $70+(18 \%)$ & 43 & 19 & 38 \\
\hline \multicolumn{4}{|c|}{ Colonoscopy procedure anxiety $(n=1302)$} \\
\hline - Score<70(71\%) & 24 & 25 & 51 \\
\hline - Score $70+(29 \%)$ & 31 & 24 & 45 \\
\hline \multicolumn{4}{|c|}{ Colonoscopy results anxiety $(n=1301)$} \\
\hline - Score $<70(72 \%)$ & 25 & 25 & 50 \\
\hline - Score $70+(28 \%)$ & 29 & 23 & 48 \\
\hline \multicolumn{4}{|c|}{ Purpose of colonoscopy $(n=1301)$} \\
\hline - Screening (25\%) & 22 & 25 & 53 \\
\hline - Surveillance (21\%) & 26 & 25 & 49 \\
\hline - Symptoms (54\%) & 29 & 23 & 48 \\
\hline \multicolumn{4}{|c|}{ Time of colonoscopy $(n=1331)$} \\
\hline - Before 1000h (28\%) & 28 & 22 & 49 \\
\hline - 1000 to $1200 \mathrm{~h}(26 \%)$ & 29 & 24 & 27 \\
\hline - Afternoon (36\%) & 23 & 26 & 51 \\
\hline
\end{tabular}

Number of previous colonoscopies $(n=1322)$

\begin{tabular}{|l|l|l|l|}
\hline$-0(42 \%)$ & 24 & 23 & 53 \\
\hline$-1(25 \%)$ & 27 & 25 & 48 \\
\hline $.2+(33 \%)$ & 29 & 25 & 46 \\
\hline
\end{tabular}

Type of bowel prep (multiple responses allowed)

- 4-L PEG (43\%)

- Pico-Salax (55\%)

\begin{tabular}{l|l|l}
31 & 22 & 47
\end{tabular}

- Adjunctive agent (52\%)

23

$26 \quad 51$

- 2-L PEG (1\%)

\begin{tabular}{|l|l|}
\hline 25 & 23 \\
\hline 35 & 2 \\
\hline
\end{tabular}

When last saw scope doctor $(n=1315)$

- Never (direct scope) (41\%) 25

- $\leq 6$ months ago (46\%) $\quad 28$

- $>6$ months ago (13\%)

25

\begin{tabular}{|l|l|}
\hline 25 & 50 \\
\hline 22 & 49 \\
\hline 27 & 48 \\
\hline
\end{tabular}

Finished laxative for current colonoscopy $(n=1320)$

- Yes-finished $(87 \%)$

- No-unfinished (13\%)

25

23

51

${ }^{1} P$ value for group differences $<0.01$. 
- Table 2 Predictors of reluctance to use early morning bowel preparation-adjusted logistic regression analysis.

\begin{tabular}{|c|c|c|}
\hline & $\begin{array}{l}\text { Model 1: } \\
\text { Reluctant vs. } \\
\text { Willing } \\
\text { ( } \mathrm{n}=772), \text { Odds } \\
\text { ratio }(95 \% \mathrm{Cl})\end{array}$ & $\begin{array}{l}\text { Model 2: } \\
\text { Reluctant vs. } \\
\text { Neutral } \\
\text { ( } n=515), \text { Odds } \\
\text { ratio }(95 \% \mathrm{Cl})\end{array}$ \\
\hline \multicolumn{3}{|c|}{ Demographic of respondent } \\
\hline Female & $1.65(1.19-2.29)^{2}$ & $1.46(0.99-2.16)$ \\
\hline \multicolumn{3}{|c|}{ Age, years (reference $=16-39$ years) } \\
\hline - $40-59$ & $0.87(0.51-1.49)$ & $1.16(0.64-2.11)$ \\
\hline - $60-91$ & $1.00(0.57-1.76)$ & $1.30(0.69-2.45)$ \\
\hline Married & $1.03(0.71-1.50)$ & $0.94(0.61-1.43)$ \\
\hline $\begin{array}{l}\text { Post-secondary } \\
\text { education }\end{array}$ & $0.99(0.70-1.40)$ & $1.48(1.00-2.21)$ \\
\hline \multicolumn{3}{|c|}{ Prep information received and anxiety of respondent } \\
\hline $\begin{array}{l}\text { Number of previous } \\
\text { colonoscopies }^{3}\end{array}$ & $1.20(1.07-1.35)^{2}$ & $1.13(0.99-1.29)$ \\
\hline $\begin{array}{l}\text { Received "Right" } \\
\text { amount of prep info }\end{array}$ & $0.95(0.67-1.34)$ & $0.93(0.62-1.38)$ \\
\hline $\begin{array}{l}\text { Bowel prep informa- } \\
\text { tion was unclear }{ }^{4}\end{array}$ & $1.86(1.21-2.85)^{2}$ & $1.70(1.04-2.77)^{1}$ \\
\hline $\begin{array}{l}\text { Bowel preparation } \\
\text { anxiety score }>70\end{array}$ & $2.02(1.35-3.02)^{2}$ & $2.18(1.34-3.55)^{2}$ \\
\hline $\begin{array}{l}\text { Scope procedure } \\
\text { anxiety score }>70\end{array}$ & $1.24(0.85-1.80)$ & $1.06(0.68-1.65)$ \\
\hline $\begin{array}{l}\text { Scope results anxiety } \\
\text { score }>70\end{array}$ & $0.94(0.65-1.37)$ & $1.07(0.69-1.67)$ \\
\hline \multicolumn{3}{|c|}{ Details of respondent's current colonoscopy } \\
\hline Purpose is symptoms & $1.40(0.99-1.97)^{1}$ & $1.62(1.10-2.38)^{1}$ \\
\hline $\begin{array}{l}\text { Appointment is after } \\
1200 \mathrm{~h}\end{array}$ & $0.90(0.62-1.31)$ & $0.72(0.47-1.10)$ \\
\hline $\begin{array}{l}\text { Type of laxative is } 4 \mathrm{~L} \\
\text { of PEG }\end{array}$ & $1.45(1.02-2.06)^{1}$ & $1.57(1.03-2.39)^{1}$ \\
\hline $\begin{array}{l}\text { Adjunctive agent in } \\
\text { laxative }\end{array}$ & $0.95(0.68-1.31)$ & $0.92(0.63-1.34)$ \\
\hline Direct to scope & $0.97(0.70-1.36)$ & $0.76(0.52-1.11)$ \\
\hline $\begin{array}{l}\text { No split bowel } \\
\text { preparation }\end{array}$ & $1.96(1.31-2.93)^{2}$ & $1.42(0.88-2.27)$ \\
\hline $\begin{array}{l}\text { Did not finished } \\
\text { laxative }\end{array}$ & $1.66(1.01-2.73)^{1}$ & $0.85(0.49-1.47)$ \\
\hline \multicolumn{3}{|c|}{$\begin{array}{l}1 P \text { value }<0.05 \text {. } \\
2 P \text { value }<0.01 \text {. } \\
{ }^{3} \text { Odds ratio is per previous colonoscopy. For example, an individual with } 3 \\
\text { previous colonoscopies is estimated to be } 1.20^{3}=1.73 \text { times more likely } \\
\text { than an individual with } 0 \text { previous colonoscopies to be reluctant than will- } \\
\text { ing to undergo SDBP. }\end{array}$} \\
\hline
\end{tabular}

\section{Discussion}

Among patients who were about to undergo a colonoscopy, approximately three-quarters were willing or neutral to wake early for BP for repeat colonoscopy. On the one hand, this indicates a significant proportion of patients who suggest that they would comply with SDBP if their endoscopists advised it. That said, one-quarter would be reluctant to conduct SDBP even if it were requested by their endoscopist; so we assessed determinants of reluctance.

In our study, there was a striking similarity in odds ratios in the model predicting reluctant versus willing to undergo early morning BP ( $\vee$ Table 2, Model 1$)$, and that predicting reluctant versus willing or neutral (Supplementary Table 1, Model 3); this suggests that people who state that they are neutral toward early morning BP would likely behave similarly to those who state that they are willing to conduct an early morning BP. The predictors of reluctance were female gender, higher number of previous colonoscopies, high levels of anxiety about BP, perceived inadequacy of received BP information, the purpose of the current colonoscopy being symptoms, having used $4 \mathrm{~L}$ of PEG laxative for the current colonoscopy, not having split the BP for the current colonoscopy, and not having finished the laxative. Importantly, age, lower education level, presenting directly for colonoscopy without a prior visit with the endoscopist, and the timing of the current colonoscopy had no association with reluctance to wake up early for BP for a subsequent colonoscopy. An understanding of these predictors may help in developing approaches to increase the use of SDBP and the early waking that this requires of some patients.

There are a number of approaches that could be taken to reduce reluctance to wake early for BP. As suggested in previous studies [21,27], we found that high anxiety about the BP was consistently associated with reluctance to wake early in the morning to complete BP. There has been limited research on interventions to reduce anxiety around colonoscopy. Although some randomized controlled trials suggest that providing more user friendly written materials and videos explaining how to conduct the BP appear to be effective in lowering anxiety [28-30], the effects have not been consistent [31], which may be related to the content of the information provided. An- 
other suggestion is to allow more time with the patient before the colonoscopy [32]. More work exploring ways to mitigate anxiety may result in an increased likelihood that patients would be willing to wake early for BP.

Respondents who had undergone previous colonoscopies were more reluctant to wake early for BP for their next colonoscopy, and the reluctance increased with each prior colonoscopy. It is possible that they had not used SDBP previously and had a "successful" colonoscopy so did not feel that early morning waking for the second dose of SDBP was necessary. More widespread use of SDBP is relatively recent and people with previous colonoscopies likely used the day before method for prior colonoscopies. However, the quality of colon cleansing has not been routinely documented [33] or communicated to patients until recently and therefore it is possible that some of the patients with prior colonoscopies had inadequate prior examination leading to early repeat colonoscopy.

It is notable that $30 \%$ of respondents indicated that they did not receive enough information before the colonoscopy and a further $4 \%$ indicated that they received no information ( $\triangleright$ Table 1). Improved information sharing and educational resources, developed with assistance from patients experienced with colonoscopy, may help to reduce problems with instructions that are not clear to some patients. Although the amount of information received was not associated with reluctance to undergo early morning SDBP, improved messages to patients about the advantages of split dose, integrated with instructions about BP, may also decrease reluctance.

Reluctance to wake up early in the morning for BP was higher among individuals who used large volume BP laxative for a colonoscopy. One could anticipate this reluctance as it takes longer to consume large volume BP, which then would leave either shorter travel time to the endoscopy unit or the need to wake up even earlier. In this regard, the results of the recent Italian study where $38 \%$ of the study participants did not take the SDBP even though they were informed about the benefits of SDBP, likely do not apply to settings using lower volume BP [20].

The results of our study are consistent with those of randomized controlled trials, which have reported higher willingness to repeat colonoscopy with the same method among those undergoing SDBP than day before BP [17]. In our study in routine clinical practice, those who had split their bowel preparation for the current colonoscopy were more likely to be willing to undergo early morning BP for their next colonoscopy. It is possible that this is a result of selection bias - those who would be willing to undergo early morning $B P$ in the future were also willing (and did) to undergo SDBP for their current colonoscopy. It may also suggest that the fear of the unknown may be a greater barrier to administering a morning BP than is the actual discomfort of the morning BP. An educational tool, such as a video with narratives from colonoscopy patients who had conducted SDBP and not found it too difficult, may help those who have never undergone SDBP to be comfortable with a suggestion of waking early for BP.

The documented benefits of SDBP $[12-17,19]$ suggest that it would be helpful to consider what administrative changes might encourage increased use of SDBP for morning colonoscopies. One approach might be to ask at the stage of the referral whether the patient would accept a morning colonoscopy that would involve early wakening to complete the BP. Our survey suggests that many people would accept this option. For some, this may even be a preferred option since early morning colonoscopies allow individuals to resume their normal diet earlier in the day. Those who indicated a preference not to have early appointments would be scheduled for later appointments. If many people chose later day appointments, there might be a longer wait for these appointments than for early in the day appointments. The offer to schedule later day appointments could be prioritized; for example, depending on the demand, it could be restricted to those advised to have frequent colonoscopies, such as those with Lynch syndrome and IBD patients with prior documented dysplasia.

\section{Limitations and strengths}

The results of this study should be considered in the context of strengths and limitations.

To ensure the survey length remained reasonable for completion, we limited the number of questions asked about waking early for a morning colonoscopy. We did not explore reasons for reluctance with direct questions, or explore options for reducing reluctance in this study. Furthermore, some respondents would have had to travel some distance to the colonoscopy location on the day of the procedure and this may have been a factor for these patients. We did not gather information about the time required to travel to the colonoscopy location. Similar to other survey studies, this study is potentially subject to socially desirable response bias and opinions may or may not reflect future behavior. Our results show associations between various patient characteristics and reluctance to conduct early morning BP, and these should be interpreted cautiously; associations differ from cause and effect. Although we know the characteristics of those who participated in this study, we do not know the characteristics of those who did not participate. We were therefore unable to assess whether those who participated differed from those who did not in a way which may have impacted the generalizability of our results.

The strengths of this study include a large and diverse sample recruited from routine city-wide clinical practices. Participants had a range of previous experience with colonoscopy and a variety of different indications for the procedure and this is typical of clinical practice. Our multiple analyses provided consistent results: in addition to the ordinary logistic regression, we assessed the assumptions for, and then conducted, an ordinal logistic regression. In both methods of logistic regression, results were nearly the same (compare > Table 2 with Supplementary Table 1 ), strengthening the reliability of our findings.

\section{Conclusions}

The majority of respondents to our survey indicated that they were neutral toward or willing to administer an early morning BP; however, a substantial proportion (approximately one- 
quarter) would be reluctant to undertake a SBDP. As the advantages of an SDBP are strong and most patients would be willing to undertake a SDBP if asked to, endoscopists and family physicians should not hesitate to suggest splitting the dose to their patients, even if the colonoscopy will be early in the morning. It will also be important to develop strategies to improve acceptance of early morning wakening for BP among those who continue to be reluctant. Addressing modifiable factors, such as improving BP information, allaying BP-related anxiety and use of low volume BP may increase acceptance of SDBP among patients and colonoscopists for early morning colonoscopies.

\section{Acknowledgements}

Ms Celeste Waldman died during the duration of the study; she was involved in the development of the study, leading the conduct of the study and the first set of analysis. All other authors were involved in the analysis and interpretation of data and critical revision of the manuscript for important intellectual content. Drs Walker, Sisler, Park, Bernstein, Restall, Wittmeier and Singh were involved in the study concept and design. Dr Shafer performed the analysis and wrote the first draft. Dr Bernstein is supported in part by the Bingham Chair in Gastroenterology. Dr Singh has been on the advisory board of Pendopharm and Ferring and has received research funding from Merck Canada. Dr Bernstein has served on advisory boards for Abbvie Canada, Ferring Canada, Janssen Canada, Shire Canada, Pfizer Canada and Takeda Canada. He has consulted to Mylan Pharmaceuticals and Bristol Myers Squibb. He has received unrestricted educational grants from Abbvie Canada, Janssen Canada, Shire Canada, and Takeda Canada. He has been on speaker's bureau for Abbvie Canada, Ferring Canada, and Shire Canada.

\section{Competing interests}

None

\section{References}

[1] Rex DK. Optimal bowel preparation a practical guide for clinicians. Nat Rev Gastroenterol Hepatol 2014; 11: 419-425

[2] Lebwohl B, Kastrinos F, Glick M et al. The impact of suboptimal bowel preparation on adenoma miss rates and the factors associated with early repeat colonoscopy. Gastrointest Endosc 2011; 73: 1207-1214

[3] Saltzman JR, Cash BD, Pasha SF et al. Bowel preparation before colonoscopy. Gastrointest Endosc 2015; 81: 781-794

[4] Johnson DA, Barkun AN, Cohen LB et al. Optimizing adequacy of bowel cleansing for colonoscopy: recommendations from the US multi-society task force on colorectal cancer. Am J Gastroenterol 2014; 109: 1528

[5] Nichols RL, Smith JW, Garcia RY et al. Current practices of preoperative bowel preparation among North American colorectal surgeons. Clin Infect Dis 1997; 24: 609-619

[6] Frommer D. Cleansing ability and tolerance of three bowel preparations for colonoscopy. Dis Colon Rectum 1997; 40: 100 - 104
[7] de Leone A, Tamayo D, Fiori G et al. Same-day 2-L PEG-citrate-simethicone plus bisacodyl vs. split 4-L PEG: Bowel cleansing for latemorning colonoscopy. World J Gastrointest Endosc 2013; 5: 433

[8] Henderson JM, Barnett JL, Turgeon DK et al. Single-day, divided-dose oral sodium phosphate laxative versus intestinal lavage as preparation for colonoscopy: efficacy and patient tolerance. Gastrointest Endosc 1995; 42: $238-243$

[9] Rex DK, Imperiale TF, Latinovich DR et al. Impact of bowel preparation on efficiency and cost of colonoscopy. Am J Gastroenterol 2002; 97: $1696-1700$

[10] Park SS, Sinn DH, Kim Y-H et al. Efficacy and tolerability of split-dose magnesium citrate: low-volume (2 liters) polyethylene glycol vs. single- or split-dose polyethylene glycol bowel preparation for morning colonoscopy. Am J Gastroenterol 2010; 105: 1319-1326

[11] Horton N, Garber A, Hasson $\mathrm{H}$ et al. Impact of single-vs. split-dose low-volume bowel preparations on bowel movement kinetics, patient inconvenience, and polyp detection: a prospective trial. Am J Gastroenterol 2016; 111: 1330-1337

[12] Kilgore TW, Abdinoor AA, Szary NM et al. Bowel preparation with split-dose polyethylene glycol before colonoscopy: a meta-analysis of randomized controlled trials. Gastrointest Endosc 2011; 73: $1240-$ 1245

[13] Enestvedt BK, Tofani C, Laine LA et al. 4-Liter split-dose polyethylene glycol is superior to other bowel preparations, based on systematic review and meta-analysis. Clin Gastroenterol Hepatol 2012; 10: $1225-1231$

[14] El SayedAM, Kanafani ZA, Mourad FH et al. A randomized single-blind trial of whole versus split-dose polyethylene glycol-electrolyte solution for colonoscopy preparation. Gastrointest Endosc 2003; 58: 36 40

[15] Bucci C, Rotondano G, Hassan C et al. Optimal bowel cleansing for colonoscopy: split the dose! A series of meta-analyses of controlled studies Gastrointest Endosc 2014; 80: 566 - 576. e562

[16] Cohen LB. Split dosing of bowel preparations for colonoscopy: an analysis of its efficacy, safety, and tolerability. Gastrointest Endosc 2010; 72: $406-412$

[17] Martel M, Barkun AN, Menard C et al. Split-dose preparations are superior to day-before bowel cleansing regimens: a meta-analysis. Gastroenterology 2015; 149: 79-88

[18] Mathus-Vliegen E, Pellisé M, Heresbach D et al. Consensus guidelines for the use of bowel preparation prior to colonic diagnostic procedures: colonoscopy and small bowel video capsule endoscopy. Curr Med Res Opin 2013; 29: 931 - 945

[19] Hassan C, Bretthauer M, Kaminski M et al. Bowel preparation for colonoscopy: European Society of Gastrointestinal Endoscopy (ESGE) guideline. Endoscopy 2013; 45: 142-155

[20] Radaelli F, Paggi S, Repici A et al. Barriers against split-dose bowel preparation for colonoscopy. Gut 2017; 66: 1428-1433

[21] Sharara AI, Mrad RRA. The modern bowel preparation in colonoscopy. Gastroenterol Clin North Am 2013; 42: 577- 598

[22] Unger RZ, Amstutz SP, Seo DH et al. Willingness to undergo split-dose bowel preparation for colonoscopy and compliance with split-dose instructions. Dig Dis Sci 2010; 55: 2030 - 2034

[23] Menees SB, Kim HM, Wren P et al. Patient compliance and suboptimal bowel preparation with split-dose bowel regimen in average-risk screening colonoscopy. Gastrointest Endosc 2014; 79: 811 - 820. e813

[24] Facco E, Zanette G, Favero L et al. Toward the validation of visual analogue scale for anxiety. Anesth Prog 2011; 58: 8-13

[25] Facco E, Stellini E, Bacci C et al. Validation of visual analogue scale for anxiety (VAS-A) in preanesthesia evaluation. Minerva Anestesiol 2013; 79: 1389-1395 
[26] Peng C-Y], Lee KL, Ingersoll GM. An introduction to logistic regression analysis and reporting. J Educ Res 2002; 96: 3-14

[27] Voiosu A, Tantau A, Garbulet C. Factors affecting colonoscopy comfort and compliance: a questionnaire based multicenter study. Rom J Intern Med 2014; 52: 151 - 157

[28] Hsueh F-C, Chen C-M, Sun C-A et al. A study on the effects of a health education intervention on anxiety and pain during colonoscopy procedures. J Nurs Res 2016; 24: 181 - 189

[29] Arabul M, Kandemır A, Çelık M et al. Impact of an information video before colonoscopy on patient satisfaction and anxiety. Turk J Gastroenterol 2011; 23: 523-529
[30] Shaikh AA, Hussain SM, Rahn S et al. Effect of an educational pamphlet on colon cancer screening: a randomized, prospective trial. Eur J Gastroenterol Hepatol 2010; 22: 444-449

[31] Bytzer P, Lindeberg B. Impact of an information video before colonoscopy on patient satisfaction and anxiety - a randomized trial. Endoscopy 2007; 39: $710-714$

[32] Bernstein C, Thorn M, Monsees K et al. A prospective study of factors that determine cecal intubation time at colonoscopy. Gastrointest Endosc 2005; 61: $72-75$

[33] Singh H, Kaita L, Taylor G et al. Practice and documentation of performance of colonoscopy in a central Canadian health region. Can J Gastroenterol Hepatol 2014; 28: 185-190 